\title{
Myocardial Perfusion Imaging Reveals Breast Cancer
}

\author{
Richard M Fleming ${ }^{1 *}$, Matthew R Fleming ${ }^{1}$, Tapan K Chaudhuri' ${ }^{2}$ and William C Dooley ${ }^{3}$ \\ ${ }^{1}$ FHHI-Omnific Imaging-Camelot, USA \\ ${ }^{2}$ Eastern Virginia Medical School, USA \\ ${ }^{3}$ Oklahoma University Health Science Center, USA \\ *Corresponding author: Richard M Fleming, PhD, MD, JD, FHHI-OmnificImaging-Camelot El Segundo, Los Angeles, CA, USA
}

Received: 眥 September 23, 2019

Published: 制 September 30, 2019

\begin{abstract}
Diagnostic evaluation of chest pain using myocardial perfusion imaging (MPI) is a common method employed to look for coronary artery disease (CAD). The isotopes used in MPI are also useful for imaging cancer, including breast cancer. We present a case where breast cancer was diagnosed using a quantitative method which simultaneously looks for cancer and CAD.
\end{abstract}

\section{Introduction}

Diagnostic evaluation of patients with chest pain may include myocardial perfusion imaging. During the initial stress imaging evaluation, differences in regional blood flow and metabolism differentiates normal coronary blood flow from abnormal - viz. ischemia. Breast cancers are also associated with increased regional blood flow and metabolism and can be seen during the initial imaging as was done in this woman. Awareness of these similarities resulted in identification and successful treatment of her breast cancer prior to further spread of the cancer.

\section{Case Report}

A 39-year old woman presented with atypical chest pain. She was referred for myocardial perfusion imaging. Following pharmacologic stress, her initial images - shown here - were acquired 5-minutes after isotope injection. A mass was identified in her right breast and was surgically removed revealing a Stage IIA breast cancer without LN involvement. Additional workup revealed no evidence of metastatic disease. The patient elected to undergo no further treatment.

\section{Discussion}

Quantitative measurement following enhancement of regional blood flow differences, which reflect both changes in metabolism and regional blood flow, can be measured to unmask ischemia and cancers [1]. These changes can reflect CAD, which is itself caused by inflammation [2], as well as pre-cancerous changes, which can also be associated with inflammation.

\section{Conclusion}

By understanding the fundamental differences in tissue resulting from changes in metabolism and regional blood flow differences, nuclear imaging can quantitatively unmask CAD and hidden cancer (Figure 1).

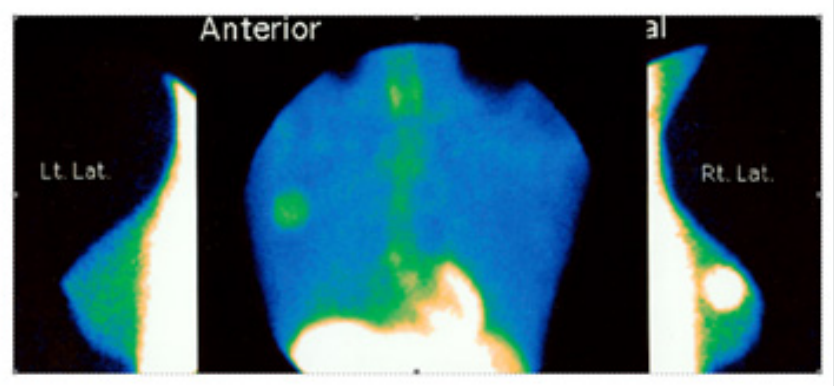

Figure 1: Figure of FMTVDM.

\section{Acknowledgment}

FMTVDM issued to first author. Figures reproduces by expressed consent of first author.

\section{References}

1. Fleming RM, Fleming MR, McKusick A, Chaudhuri TK (2018) Semiquantification limitations: FMTVDM(C) demonstrates quantified tumor response to treatment with both regional blood flow and metabolic changes. J Nucl Med 59(10): 1643-1644.

2. Fleming RM (1999) The Pathogenesis of Vascular Disease. Textbook of Angiology 787-798. 
CC (i) This work is licensed under Creative To Submit Your Article Click Here: $\quad$ Submit Article

DOI: 10.32474/OAJOM.2019.03.000157

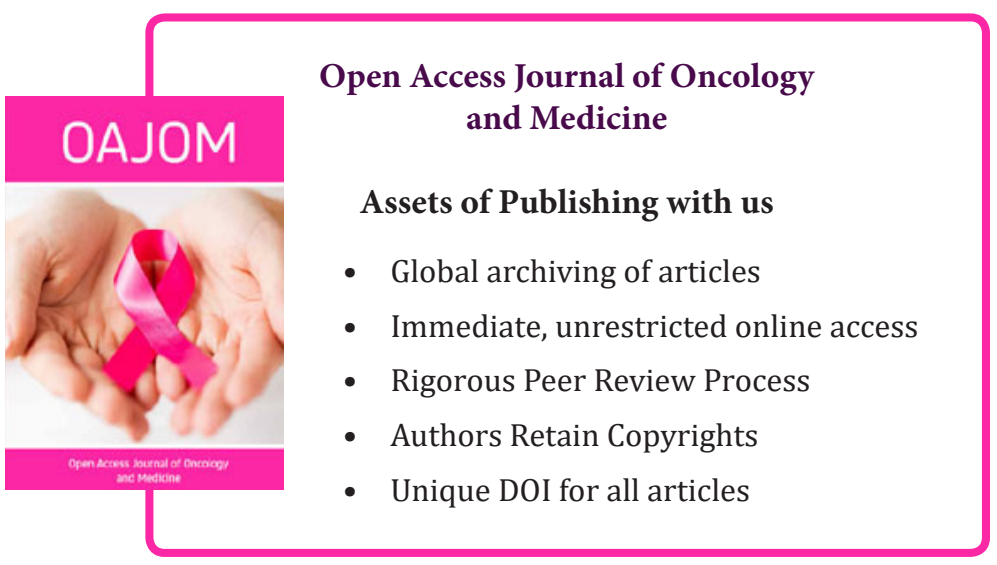

